\title{
Structure of the costume texture thickness investigation
}

\author{
Nodira Yusupova ${ }^{1 *}$, Sanovar Khamrayeva ${ }^{1}$, Jur'atbek Jabbarov ${ }^{1}$, Nigora Jabbarova ${ }^{1}$, and \\ Saida Djabbarova ${ }^{1}$ \\ ${ }^{1}$ Tashkent Institute of Textile and Light Industry, 100100 Tashkent, Uzbekistan
}

\begin{abstract}
The costume fabric is woven on the basis of tandoor sarja braids. Such textures are superficial in the body. When washing a suit sewn from the surface tissue of the body, in the process of using it only the body coverings are eroded and thinned, resulting in tissue rupture. This article presents the results of research on improving the quality, in particular, increasing the resistance to abrasion of cotton fabrics such as costume cloth. It is noted that the resistance of the fabric to abrasion depends on the indicators of its structure, that is, on the degree of mutual bending of the warp and weft threads or the supporting surface of the fabrics.
\end{abstract}

\section{Introduction}

The physical and mechanical properties of the fabrics intended for the suit are also subject to the requirements of their field of application [1]. The structure of the tissue is understood as the relative position of the body and back threads and their interdependence. The physical and mechanical properties of a fabric often depend on its weave, which affects the phase of placement of the threads in it during the weave formation, which determines the service life of the fabric, i.e. its abrasion resistance [2]. The abrasion resistance of the fabric, air permeability depends on its structural characteristics, i.e. the degree of mutual bending and density of the body and back yarns. This degree of mutual bending is determined by the area of a particular part of the body and the back yarn that can be approached by any surface, and this area is the base surface of the fabric [3]. The flattening of the base surface opens the porosity between the joints of the body, the backing threads and creates conditions for the passage of air. Therefore, in the production of fabrics for the suit, attention should be paid to the evaluation of its surface [4].

Factors related to tissue formation affect the initial parameters of tissue structure. For example, the thickness of the fabric depends on the linear densities of the body and back yarns that make it up [5]. These include factors such as the structure phase of the tissue, the shrinkage of the body and back yarns, the coefficients of filling, bonding and coating, and the base surface [6]. All of the above factors determine the structure of the tissue and the location of the threads in it.

\footnotetext{
*Corresponding author: nodira7673@gmail.com
} 
Erosion resistance increased from 17,000 to 21,000 cycles when the phase order of the tissue structure changed from 3.5 to 6.2 and the amount of base surfaces changed from $16 \%$ to $1.8 \%$ [7].

Fabrics for a suit primarily depend on its service life and their resistance to abrasion and abrasion [8]. The abrasion of the fabric depends on the unevenness of the yarn, which is assessed by the base surface of the woven fabric, i.e. the points of exit of the yarn to the fabric surface. To increase the base surface, it is necessary to change the parameters set on the loom [9].

The base surface of the fabric depends on the mutual bending heights of the body and back yarns, and the points of the yarns protruding from the surface of the fabric that touch a particular surface are called the base surface [10]. The costume fabric is woven on the basis of tandoor sarja braids. Such textures are superficial in the body. When washing a suit sewn from the surface tissue of the body, in the process of using it only the body coverings are eroded and thinned, resulting in tissue rupture $[11,12]$. The suit remains unusable even if the back coverings remain intact. Therefore, on the surface of the body surface tissue is only the output of the body coating; its resistance to abrasion is low.

\section{Materials and Methods}

Costume textures are divided into three types according to surface performance: body surface, back surface and equal surface textures. Using the method of S.A. Khamraeva [11], the base surface of the suit fabric was determined. In view of the above, the following equation for determining the thickness, the design of the structure of the suit fabric on its thickness was improved (Fig. 1).
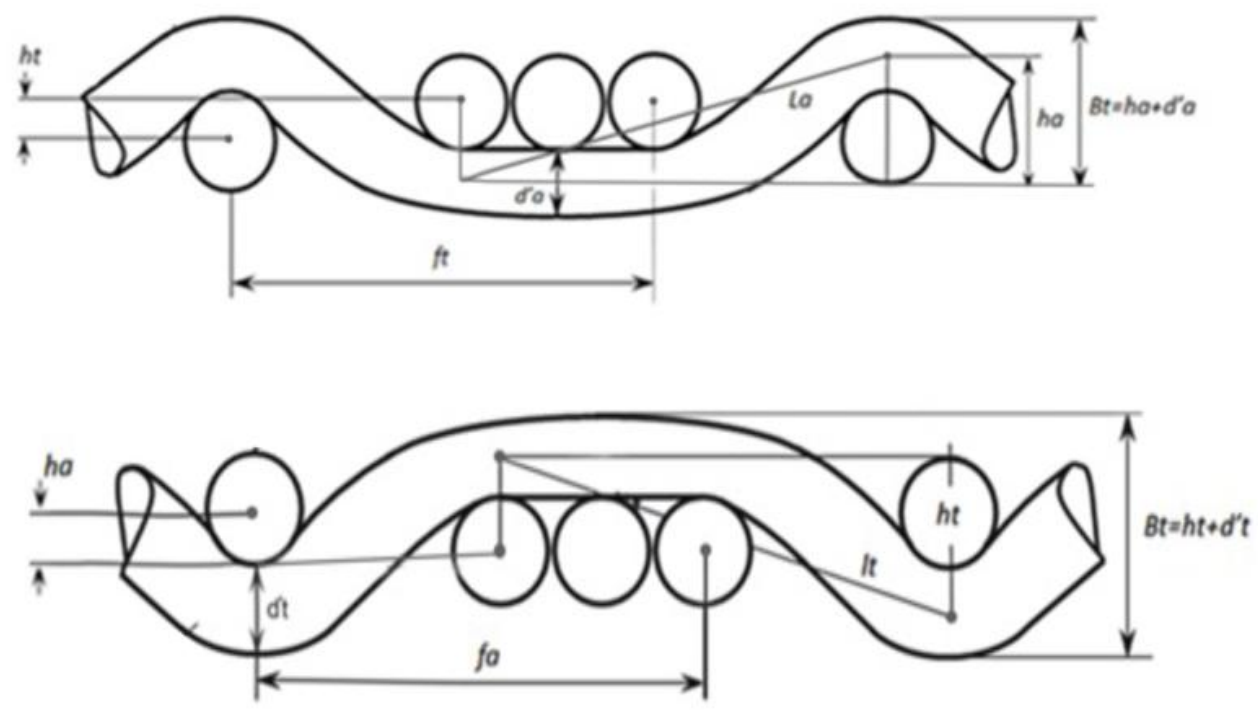

Fig. 1. Body and back surface tissue

If the tissue has a back surface, then the thickness of the tissue is determined as follows (1):

$$
\mathrm{B}_{\mathrm{a}}=\mathrm{h}_{\mathrm{a}}+\mathrm{d}_{\mathrm{a}}^{\mathrm{I}}
$$

if the body is superficial (2):

$$
\mathrm{B}_{\mathrm{t}}=\mathrm{h}_{\mathrm{t}}+\mathrm{d}_{\mathrm{t}}^{\mathrm{I}}
$$


when equal surface (3):

$$
\mathrm{B}_{\mathrm{T}}=\mathrm{h}_{\mathrm{t}}+\mathrm{h}_{\mathrm{a}}=\mathrm{d}_{\mathrm{t}}^{\mathrm{I}}+d_{a}^{I}
$$

The base surface of the fabric is assessed by the wave heights of the body and back yarns located in it.

\section{Results and Discussion}

The bending wave heights of the body and back yarns are as follows $(4,5)$ :

$$
\begin{gathered}
\mathrm{h}_{\mathrm{t}}=\sqrt{l_{t}^{2}-f_{a}^{2}}=\sqrt{\left(\frac{L_{t}}{L_{m} \cdot P_{a}}\right)^{2}-\left(\frac{1}{P_{a}}\right)^{2}}=\frac{1}{P_{a}} \sqrt{\left(\frac{L_{t}}{L_{m}}\right)^{2}-1}, \text { yarn/mm } \\
\mathrm{h}_{\mathrm{a}}=\sqrt{l_{a}^{2}-f_{t}^{2}}=\sqrt{\left(\frac{L_{a}}{L_{m} \cdot P_{t}}\right)^{2}-\left(\frac{1}{P_{t}}\right)^{2}}=\frac{1}{P_{t}} \sqrt{\left(\frac{L_{a}}{L_{m}}\right)^{2}-1}, \text { yarn } / \mathrm{mm}
\end{gathered}
$$

where, $L_{t}$ is the length of the body thread extracted and flattened from the tissue sample, $\mathrm{mm} ; L_{t}$ is the size of the tissue sample, $\mathrm{mm} ; R_{a}$ is the density of the tissue along the back, yarn $/ \mathrm{mm} ; L_{a}$ is the distance between the back threads in a single element fabric, $\mathrm{mm} ; f_{t}$ is the distance between the selected yarns in a single element fabric, $\mathrm{mm} ; L_{a}$ is the length of the backing thread pulled and flattened from the tissue sample, $\mathrm{mm}$; and $R_{t}$ is the density of yarns in the fabric, yarn $/ \mathrm{mm}$.

The calculated diameters of the threads in the body $\left(d_{t}\right)$ and back (in) before weaving are determined as follows (6):

$$
d_{t}=0,0357 \sqrt{\frac{T_{t}}{\delta}}, \quad d_{a}=0,0357 \sqrt{\frac{T_{a}}{\delta}}
$$

where, $\mathrm{T}_{\mathrm{t}}, \mathrm{T}_{\mathrm{a}}-$ linear density of tan and back yarns.

During the tissue formation process, the wrap and back yarns are compressed and the thickness of the tissue is reduced due to the approximate diameter $\left(\mathrm{d}_{t}^{\mathrm{I}}\right)$ of the compressed wrap yarn and the approximate diameter $\left(\mathrm{d}_{\mathrm{a}}^{\mathrm{I}}\right)$ of the compressed back yarn. The compression ratio $(K)$ can be determined as follows $(7)$ :

$$
K=\frac{d_{t}^{I}+d_{a}^{I}}{d_{t}+d_{a}}
$$

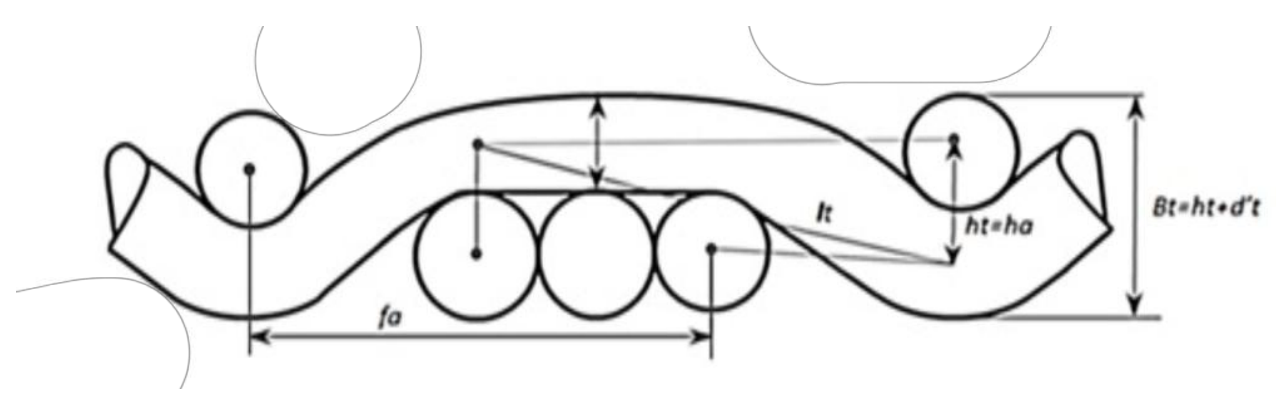

Fig. 2. Incision of smooth surface tissue 

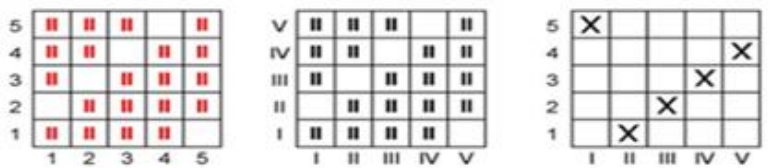

A
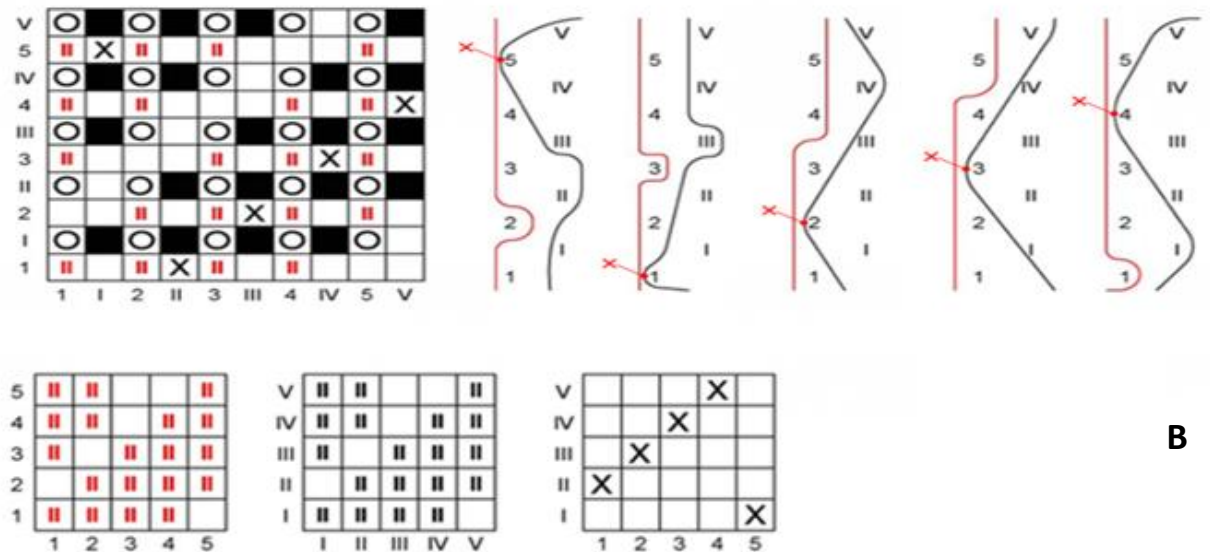

B
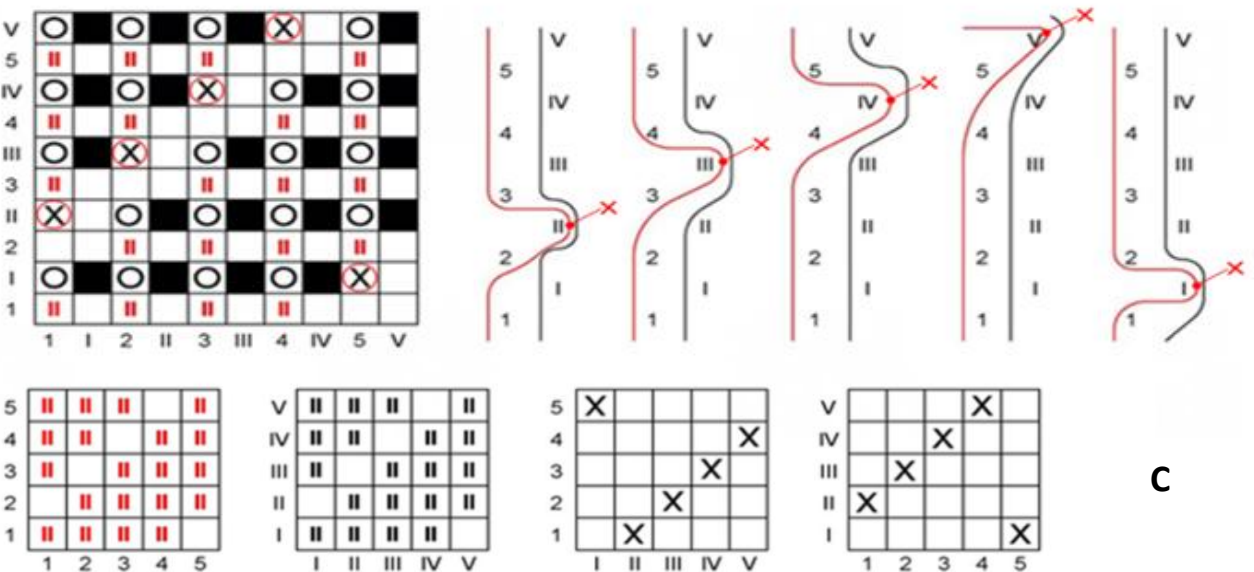

C
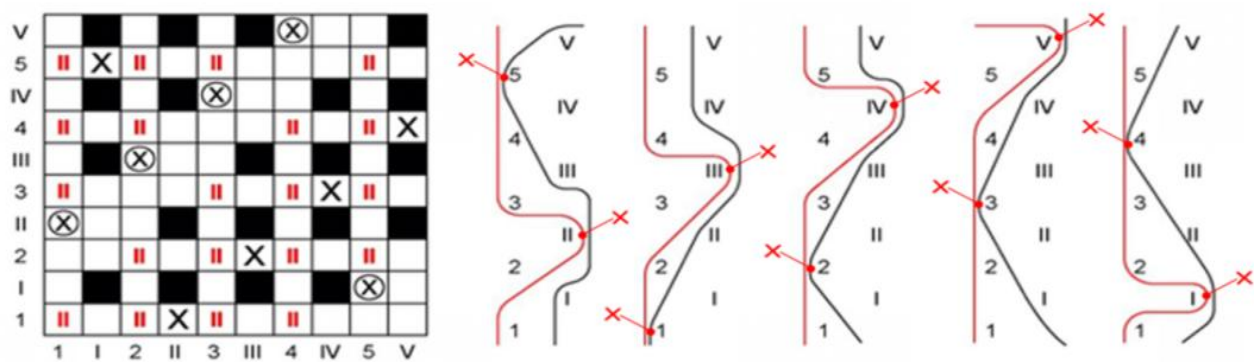

Fig. 3. Cutting of two-layer tissue on the basis of Sarja 4/1 (A. based two-layer tissue weaving by "bottom-up" bonding of layers; B. two-layer tissue weaving on the basis of "top-down" bonding of layers; and, C. two-layer tissue weaving by the method of "mixed" bonding of layers).

It is known that the sum of the diameter of the compressed back strip $\left(d_{t}{ }_{t}\right)$ with the diameter of the compressed body strip $\left(\mathrm{d}_{\mathrm{a}}^{\mathrm{I}}\right)$. 
The compression coefficient of a yarn depends on its composition, diameter, bending height of the yarns in the fabric, and the density of the fabric. Costume fabric is used in various services. If we consider the special suits of the servants, for them the suit is the main garment. They are required to have a high performance of the appearance and properties of the suit. The parameter that reflects this is the base surface of the tissue.

The abrasion resistance of the fabric depends on the exit points of the yarns to the fabric surface, i.e. the base surface. The base surface is measured by the thickness of the tissue. The design is shown in terms of the thickness of a single-layer fabric with sarja $3 / 1$ braid (Fig. 1 and Fig. 2). The surface smoothness of the produced tissue was increased (Fig. 2).

To increase the base surface of the fabric, first of all it is necessary to know which direction to change the direction of the body or back, and secondly to change the parameters of the weaving machine accordingly, which allows to improve the base surface of the fabric. By determining the thickness of the tissue, it is possible to achieve equal surface tissue production in a short time. The results of theoretical research can be used to control the thickness of the tissue and, through it, to change the base surface as well.

The design of the thickness of the fabric showed that the suit fabric produced by ARK ECO TEXTIL was found to be superficial. The shortening of the threads in the fabric plays a special role in the design of the fabric. Therefore, when designing a suit fabric, it is advisable to design on the shortening of the threads in it.

In the textile industry, as in any other industry, the modernization and improvement of technological processes allows to achieve high efficiency. Computer-aided design of a particular fabric on looms allows creating new assortments and meeting customer requirements.

Once we have implemented the program, it is possible to create similar images and print them out on a printer (see sample cropping picture in Fig. 3). Work is underway to improve this program. The application, created for intricate jacquard braided fabrics and in fabric production using an image developed by designers, has high efficiency. The production of a similar program will increase the quality of textile products and increase research in this area.

When designing fabrics for a suit, it is necessary to pay attention to the parameters that determine the quality of the fabric (depending on consumer demand): elasticity, strength, air permeability, abrasion resistance, does not lose its condition after washing and cutting of two-layer tissue on the basis of Sarja 4/1. For the design of suit fabrics for autumn and winter seasons that can meet the requirements of consumers, it was recommended to weave a two-layer fabric on the basis of Sarja 4/1 (Fig. 3).

\section{Conclusions}

The basis of the fabrics for the suit is based on Sarja weaving, which is produced in many textile enterprises around the world. On the surface of the serrated tissue, the body and back coverings are formed diagonally, on the right side of the tissue is often oriented from bottom to left, up, right. It is shown that the physical and mechanical properties of the fabric depend on the smoothness of the base surface, its shear, density and the smoothness of the yarns.

From the cuts in Fig. 3, it can be concluded that in the A and C variant cuts it was found necessary to design the fabric for the suit. The bonds in the fabric designed in this way are strong and the dimensions of the yarns are preserved after washing, which prevents the yarns from slipping. The results of the design of the suit fabric on the thickness of the suit fabric, produced by ARK ECO TEXTIL, justified the fact that the fabric is superficial. 


\section{References}

1. Zh. Meliachenko, S. Nikolaev, Izv. Universities Technol. text. prom-sti. 1(14), 47-50 (2001)

2. A. Martynova, G. Slostina, P. Vlasova, Fabric construction and design, 434 (RIO MGTA Press, Moscow, 2009)

3. N. S. Eremina, Textile industry 3, 36-38. (2013)

4. D. E. Efremov, T. Amarzhargalen, Izv. Universities. Technological text. industry 5, 4749 (2009)

5. A. Kemp, Journal of the Textile Institute 55, 66-70 (1997)

6. F. A. Onikov, L. A. Saukova, E. O. Gorbunova, Text.prom-th. 1, 50-55 (2001)

7. B. A. Olofsson, Journal of the Textile Institute 11, 54. (2004)

8. A. Robinson, R. Mares, Woven cloth Structure Manchester Textile Institute, 64- 67 (2013)

9. N. B. Yusupova, K. E. Razumeev, D. T. Nazarova, S. Sh. Tashpulatov, J. E. Danadilov, Z. B. Ongarbaeva, Izvestiya vuzov. Textile industry technology 5(383), 8588 (2019)

10. N. Yusupova, N. Nazarova, S. Khamrayeva, International Journal of Advanced Research in Science, Engineering and Technology 154(3), 6738-6742 (2018)

11. S. Khamrayeva, N. Yusupova, V. Janpaizova, N. Botaboev, B. Torebaev, Science and world International scientific journal 4(32), 12 (2016)

12. E. A. Onikov, N. Yusupova, U. B. Rajapova, S. A. Khamrayeva, R. I. Orazbayeva, Science and world International scientific journal 6(34), 11 (2016) 